\title{
Fundamental elements of university-industry interaction from a grounded theory approach
}

\author{
Rafaela Bürger and Gabriela Gonçalves Silveira Fiates \\ Universidade Federal de Santa Catarina, Florianopolis, Brazil
}

\begin{abstract}
Purpose - This work aims to analyze the university-industry interaction in innovation ecosystems. The problem under study addresses how agents can operate in university-industry interactions to enhance the connections, specifically in the aspect of operational mechanisms of an innovation ecosystem.

Design/methodology/approach - The study is qualitative, applied through grounded theory approach, cross-sectional and multiple sources of evidence - semi-structured interviews were conducted. An explanatory conceptual model was subsequently compared with the literature and validated with specialists.

Findings - The results showed that the university-industry interaction is influenced by several factors, such as networking, legal support, facilitating agents, management practices. Despite this, some other factors were identified for the improvement of U-I relationships, such as: strengthening of triple helix, greater legal certainty and encouragement of open innovation.

Research limitations/implications - The small sample size and the heterogeneity among the universities interviewed did not allow full saturation to occur. In spite of that, a significant level of saturation with respect to the challenges and barriers was observed.

Practical implications - This work has a direct dialogue with researchers, managers and actors involved in university-industry interaction with regard to increasing the capacity for creation and dissemination of knowledge among organizations, educational institutions, government and companies.

Originality/value - By adopting a grounded theory approach, a detailed research agenda addresses research needs in two main areas: activities that precede the interaction between universities and companies, and the organization and management of the consequences of collaborative relationships.
\end{abstract}

Keywords University-industry interaction, Innovation, Innovation agencies, National innovation system, Innovation ecosystem

Paper type Research paper

\section{Introduction}

Inserted in a complex economic and social context, characterized by constant changes, organizations increasingly depend on the capacity of their intellectual assets to generate ideas and create innovative products and services (Fagerberg, Lundvall, \& Srholec, 2018). Due to its important role for the development of a society, the need for companies to maintain competitive and innovative capacity is highlighted, factors that are known to determine the survival and success of these companies (Olso Manual - OECD, 2018).

According to Pinho (2018), there is no doubt about the critical role that innovation and technological capabilities play in the competitiveness of companies and also in local, regional and national development. However, for this author, although companies play central roles in

(C) Rafaela Bürger and Gabriela Gonçalves Silveira Fiates. Published in Innovation \& Management Review. Published by Emerald Publishing Limited. This article is published under the Creative Commons Attribution (CC BY 4.0) licence. Anyone may reproduce, distribute, translate and create derivative works of this article (for both commercial and non-commercial purposes), subject to full attribution to the original publication and authors. The full terms of this licence maybe seen at http:// creativecommons.org/licences/by/4.0/legalcode.

Funding: This study was financed in part by the Coordenação de Aperfeiçoamento de Pessoal de Nível Superior - Brasil (CAPES) - Finance Code 001.
Universityindustry interaction

Received 10 August 2021 Revised 21 October 2021 Accepted 21 October 2021

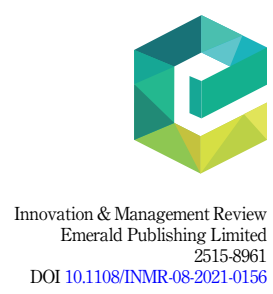


the economic development process of the market, there is a growing recognition that innovative companies cannot depend only on their internal competences (Pinho, 2018).

As a result, the growing demand for innovation and increasingly complex products and services requires companies to seek new sources of information and knowledge, such as universities (Garcia, Rapini, \& Cário, 2018). In this sense, the latent importance of promoting University-Industry interaction (U-I) is highlighted, given the positive impact in this relationship with the innovative strategies generated (Albats, Fiegenbaum, \& Cunningham, 2018). Academic research, then, appears in this analysis because it proves to be a source of new knowledge and a potential for promoting development.

Therefore, by consensus, universities, companies and the government seem to point out that economic growth with equity depends on the strengthening, expansion, consolidation and integration of the national system of science, technology and innovation (Lemos \& Cario, 2017). In this regard, the role of the instruments that support this process of U-I interaction is highlighted, so that they can offer conditions for the dissemination of knowledge aligned with science, technology and innovation (Bernardino, Debortoli, Veloso, Nunes, \& de Assis, 2020).

In this context, the present work is located, whose objective is to analyze the U-I interaction in innovation ecosystems.

The southern region of Brazil was chosen as the object of this study. Against the national numbers, south Brazilian region stands out as the one that registered the highest growth $(11.8 \%)$ in 2019 compared to other Brazilian regions, reaching 12.138 companies surveyed (ACATE, 2020). With a growth of $7.7 \%$ in the last year, the innovation ecosystem region is the sixth largest in the country in number of companies. According to a report by the State Innovation Index (FIEC, 2020), the south region occupies the second overall position in the ranking. Also, according to this report, it is the fourth region in the element "Institutional Environment". This position is also held in the ranking of Global Competitiveness in Technological Sectors (FIEC, 2020). Considering these data, evaluating the U-I interaction pattern in southern Brazilian region constitutes a relevant academic effort in order to generate results that will contribute to the formulation of policies that intensify the U-I interaction not only in the Brazilian southern region but also at national and international level.

The problematic of the study addresses how agents can operate in U-I interactions to enhance connections specifically in the aspect of operational mechanisms of an innovation ecosystem. In operating in an innovation ecosystem, companies, entrepreneurs, teaching and research institutions seek to join forces for technological development. Hence, the research question arises: How does U-I interaction occur in an innovation ecosystem?

Given this context, this article aims to analyze the U-I interaction in innovation ecosystems. The problem under study addresses how agents can operate in U-I interactions to enhance the connections specifically in the aspect of operational mechanisms of an innovation ecosystem. To this end, the article is divided into 4 sections, in addition to this introduction. Next section we discuss the theoretical perspectives that underlie the research; in 3 , the adopted methodological trajectory is presented; while 4 presents the analysis of the data with the presentation of the analysis and discussion, and Section 5 closes the article with the final considerations.

\section{Theoretical background}

According to Fagerberg et al. (2018), a company does not innovate alone. Therefore, depends on a strong interaction with the environment to promote the necessary technical changes along the technological trajectory. It is clear, then, the need for a systemic process capable of leading and stimulating the innovative processes of the various institutions that constitute a capitalist economy. The joint effort of universities, development agencies, the state, 
government laboratories and research institutes are necessary to advance the path of the technological trajectory. Such a movement can be referenced by the approach of the National Innovation System (NIS) (Nelson \& Rosenberg, 1993; Lemos \& Cario, 2017).

The NIS can be conceptualized as a set of institutions that influence the development, diffusion and use of innovations (Nelson \& Rosenberg, 1993; Edquist, 2010). Its central activity is learning, which refers to the social activity of interaction between individuals. The NIS has the characteristics of being an open and heterogeneous system that can be local and national at the same time. It is worth mentioning that the actors that make up the NIS and their relations depend on the cultural, economic and institutional characteristics of each country (Freeman, 1995; Lundvall, 2016).

Edquist (2010) explains the role of institutions and actors that create, develop and disseminate innovations, as well as the interaction channels that connect those involved. That is why, it must considered that companies are organizations inserted in the political and socioeconomic environment of the country that reflect their cultural and historical trajectory (path dependence) (Edquist, 2010). Thus, the innovation system is a set of institutions that contribute to the development of the capacity for innovation and learning of a country, region and sector (Paranhos \& Perin, 2018). The main characteristics involve the emphasis on historical trajectories and the understanding of various elements and relationships concerning the production, assimilation and diffusion of knowledge (De Vasconcelos Gomes et al., 2021). For Lundvall (2016), due to the systemic and comprehensive character of the NIS, it is important to consider in its analysis, the existence of several dimensions such as productive, social, institutional, political and financial as well as the interaction between them.

From the perspective of the NIS, universities are referred as relevant actors of innovation systems, where they play an important role in their interactions with companies, whether providing infrastructure or human resources for innovation or by promoting learning process and knowledge transfer (Suzigan \& Albuquerque, 2011; Lemos \& Cario, 2017).

Regarding the importance of promoting learning process and knowledge transfer, Fioravanti, Stocker, \& Macau (2021) arguments the existence of influence factors acting as facilitators or inhibitors such as cooperation, relationship with institutions among others. This argument reinforces the need for strong relationships between universities, industries, and other institutional actors, aiming to develop stronger learning environment.

\subsection{University-industry interaction}

Universities are actors that can contribute to economic development in a knowledge economy, because through its three main functions - teaching, research and extension - it is able to generate knowledge and promote interaction between individuals and organizations. In this perspective, the concept of "triple helix", developed by Etzkowitz and Leydesdorff (2000), highlights the relationship of mutual exchange between universities, industries and the government. In this approach, universities assume a "commitment" to economic and social development, characterizing themselves as entrepreneurial universities. Thus, in addition to its functions of training human resources and scientific research, the university has acquired a new role in today's society, contributing directly to the creation of new products and services (Paranhos \& Perin, 2018).

To provide more dynamism and enhance integration among the actors, Bernardino et al. (2020), using a case study, discuss the role of institutions, such as Research Support Foundations, fundamental agents for innovation, that fosters and strengthen the bonds between the Triple Helix elements.

However, it is worth mentioning that this interaction does not occur in all areas of knowledge. Lundvall (2016) points out that this cooperation between universities and

\section{University- industry interaction}


companies is more likely in certain sectors, such as those with a scientific basis, like engineering, chemistry, pharmacy and electronic. This fact increases the relevance of research and development (R\&D) laboratories in educational institutions and attributes to these departments the permanent function of generating technological sources relevant to innovation (Lemos \& Cario, 2017). Learning takes on a prominent place in the NIS, which is why its accumulation is considered an integral part of the production process with $R \& D$ activities (Lundvall, 2016).

Paranhos and Perin (2018) highlight the growing strengthening of interaction relations between universities and the industrial sector as one of the forms currently used that contribute significantly to the generation of innovation and economic growth. The intensity of the relationship is guided by issues such as the historical trajectory of each country, its laws and regulations, the stage of development of each sector and the degree of knowledge accumulated in each company, in other words, its historical context (Lemos \& Cario, 2017).

Thus, the links established in the interaction generate scientific and technological productions and these, in turn, play a relevant role in the generation of innovative processes (Scandura, 2016). Consequently, universities generate scientific knowledge and companies are responsible for the transformation and application of this knowledge generated in new technologies (Lemos \& Cario, 2017). Lundvall (2016) state that this process becomes cyclical as companies, accumulating technological knowledge, allow new issues to be transformed into universities into research objects, thus contributing to the productive development of the chain as a whole.

Universities, therefore, are identified as fundamental institutional actors in innovation systems, since their role goes beyond the formation of qualified labor, as they also represent a source of technological and industrial knowledge for the productive sector (Fagerberg et al., 2018).

This article tries to address the gaps concerning U-I interactions while considering its systemic, nonlinear, interactive and socially determined character. This academic endeavor is focused on southern Brazilian region due to its relevance both in representation as a Brazilian innovation ecosystem and as a great player and promoter of $\mathrm{U}-\mathrm{I}$ interaction.

\section{Methodological procedures}

Most research on U-I interaction focuses on the firm's side (Freitas, Marques, \& e Silva, 2013; Scandura, 2016; Puffal, Ruffoni, \& Spricigo, 2021). However, little attention has been paid to the perspective of research groups and innovation agencies that are central players in the U-I interaction process.

In addition, literature that discusses U-I collaborations is mostly quantitative research or use case studies (Lehmann \& Menter, 2016; Scandura, 2016; Rajalo \& Vadi, 2017; Albats et al., 2018). This research brings a different way of analyzing the interaction, through the understanding of the collaboration emerging from the data set, demonstrating the systemic relationship of the operational mechanisms, and considering context, benefits, challenges and bases for an ideal U-I relationship.

To analyze how the U-I interaction occurs in south Brazil, a Grounded Theory approach was adopted (Corbin \& Strauss, 2015). With a longitudinal analysis of cross-sectional data, eight coordinators of research groups and four managers of innovation agencies from southern Brazilian universities were interviewed (see Table 1 for an overview of the actors).

The subjects were selected based on the identification of the degree of interaction between research groups and companies, which was found on a Brazilian data base (CNPq Research Groups dataset). This criterion is justified from the objective of understanding the U-I interaction in general, relevant to different areas, inserted in different contexts.

A key approach to limiting personal bias is to interview well-informed individuals who perceive phenomena from a deep perspective (Eisenhardt \& Graebner, 2007). Notably, 


\begin{tabular}{|c|c|c|}
\hline University* & Interviewed actors** & ity- \\
\hline University 1 & $\begin{array}{l}3 \text { Researchers (mechanical and electrical engineering and pharmacy) } \\
1 \text { Manager of the innovation agency (SINOVA) }\end{array}$ & interaction \\
\hline University 2 & $\begin{array}{l}1 \text { Researcher (industrial technology) } \\
1 \text { Manager of the innovation agency (NIT) }\end{array}$ & \\
\hline University 3 & $\begin{array}{l}1 \text { Researcher (mechanical engineering) } \\
1 \text { Manager of the innovation agency (NIT) }\end{array}$ & \\
\hline University 4 & 1 Researcher (business) & \\
\hline University 5 & 1 Manager of the innovation agency (AGIT) & \\
\hline University 6 & 1 Manager of the innovation agency (NIT) & \\
\hline University 7 & 1 Researcher (business) & \\
\hline \multicolumn{2}{|c|}{$\begin{array}{l}\text { Note(s): *The names of the universities were removed to maintain the confidentiality of the respondents. } \\
\text { NAll researchers are also academic professors } \\
\text { Source(s): Research data }\end{array}$} & $\begin{array}{r}\text { Table } 1 . \\
\text { Characterization of } \\
\text { respondents }\end{array}$ \\
\hline
\end{tabular}

the actors differ in, for example, universities, knowledge area, time of experience of the interviewee in U-I interaction, institutional and local environments - increasing the generalization of results in the case of comparable results (Eisenhardt \& Graebner, 2007). In these interviews, not only the contexts of the interactions were identified but also other important aspects to understand the phenomenon (for example, practices, consequences/ benefits, barriers/challenges and the scenario idealized by the interviewee as ideal).

Data analysis was performed using the content analysis technique (Bardin, 2014). As a result, an explanatory conceptual model about the U-I interaction was generated. This model was subsequently validated with two new subjects who experience the researched phenomenon. From the validation, some aspects were modified, mainly with regard to the understanding of the codes and also the insertion of levels within the axial codes (see Figure 1 explanatory conceptual model after validation).

After the analysis and validation of the theoretical model, we turned to the literature, aiming to compare and discuss the model with previous research on the theme. As a result, it was verified how the U-I interaction occurs in southern Brazilian region. Based on this diagnosis, it was possible to create proposals on how to stimulate and promote the advancement of the U-I interaction. Table 2 summarizes the methodological process of the research.

\section{Analysis and discussion}

Innovation is recognized as a source of survival and growth for companies, as well as an important element in explaining the wealth of regions and nations. The relationship between the production of scientific and technological knowledge plays an important role in the development of innovation (de Souza et al., 2019). In developed countries, it is possible to identify the existence of a feedback mechanism between these two dimensions (Puffal et al., 2021). However, in developing countries, such as Brazil, this flow is less dynamic due to fewer interactions between universities and industries (Suzigan \& Albuquerque, 2011; Fischer, Schaeffer, \& Vonortas, 2019).

It is important to note some specificities of the Brazilian context considering the relationship between U-I interaction. Many Brazilian companies that want to innovate often do not invest in interaction with universities. Instead, the innovative activity is more related to the purchase of modern machinery and equipment and to the interaction with customers and suppliers (Puffal et al., 2021). 
INMR

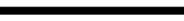

Figure 1.

Analytical model after

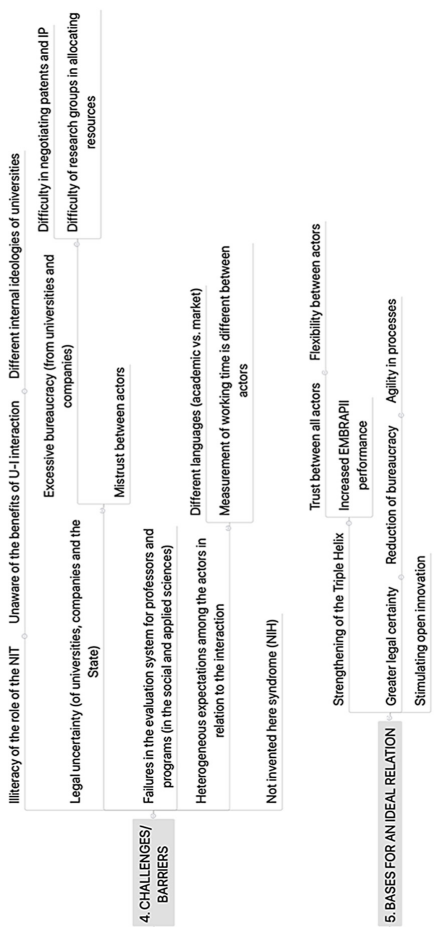

validation 


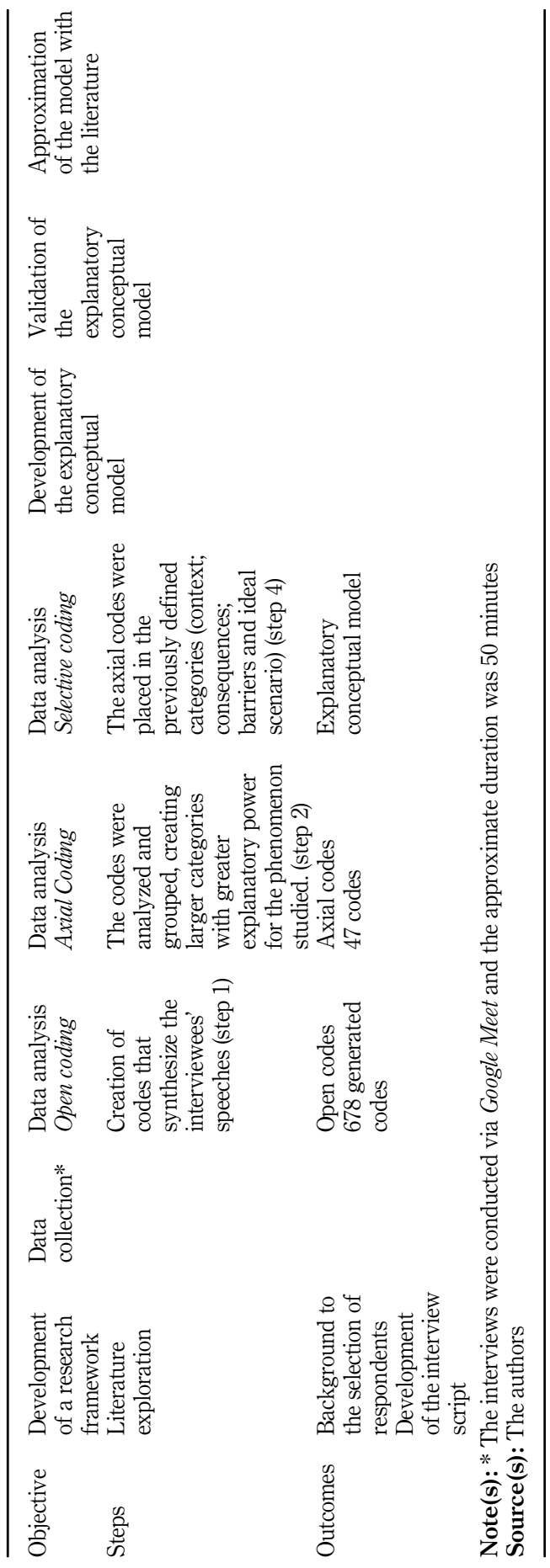

Universityindustry interaction

Table 2. Methodological process 
Hence, analyzing this relationship observing the context, barriers and benefits for the participants becomes a preponderant factor to encourage and stimulate greater innovation through the collaboration between Brazilian universities and companies.

The model presented in Figure 1 provides an explanation of how the U-I interaction occurs in southern Brazilian region. The conceptual scheme was built from the perception of the coordinators of research groups and from the managers of the innovative agencies. As a result, we present the main elements involved in this process and their interrelationship.

The constructed model can be considered a portrait of reality, which initially presents the context of U-I interactions. According to the model by Corbin and Strauss (2015), the context of the phenomenon concerns the location and the conditions that favor or hinder its development. Then, the practices used to promote U-I interaction were mapped, based on the perception of relevant evidence for this process. The next stage of the analysis sought to understand the consequences and benefits of the U-I interaction, in the perception of the interviewed actors. Subsequently, the challenges and barriers present in the interaction that hinder the exchange process between universities and companies were investigated. It was at this moment that the interviewees highlighted factors necessary to enhance the interactions, that is, elements necessary for an "ideal scenario" of U-I interaction, finalizing the theoretical model.

\subsection{Context}

It is a fact that some areas of knowledge are more likely to develop innovation and applications in the industry compared to others. There are academic environments in which the teaching and learning process itself is already an incubator of ideas, developing technology through products and services. This reality is explicit in the speech of the directors of the innovation agencies when they mention that the area of engineering, pharmacy, biology and chemistry are the main representatives of U-I interaction. Teachers agree with this perspective as they demonstrate that it is not possible to promote quality teaching, without placing the student in the face of real market problems. As explained in the interviews, it is clear that the group coordinators are aware of this need to include research in the industrial environment and even reveal in the testimonies that this is one of the motivations for working together with companies.

For the interviewees, this need to combine theory and (market) practices arises from the conception that knowledge is distributed, that is, no actor (university, researchers, company or government entities) has complete knowledge and information on all factors that influence the development of a particular innovation. Respondents stress the importance of bringing together these different types of information to reach the "frontier of knowledge", developing something really disruptive, innovative and, above all, applicable.

The agents that are external to the interaction (university management and government) play an important role in narrowing and making these interactions feasible. Around this, the interviewees point out that university management participate actively in the creation of mechanisms that facilitate or hinder U-I interaction. According to one of the interviewees, having a rector focused and related to the area of innovation was a major factor in the development of U-I interaction of the university in general. While another researcher points out that the university's internal rules make interaction very difficult.

Among facilities and difficulties, it is worth highlighting the social role of the university exposed by the interviewees. It seems to have a general understanding that the university, as it is inserted in a certain region, with specific social, cultural norms and economic factors, has the prerogative to contribute to its region. Respondents state that one of the forms of contribution is the U-I interaction.

Still related to external agents another mechanism mentioned was the tax incentive given by the government to companies that collaborate in partnership with universities. According 
to one interviewee, this is one of the main reasons for companies to seek interaction with universities.

An additional factor that directly influences the phenomenon is the state of "health" of the economy. Whereas the crisis directly compromises the scientific and technological development of a country, reducing the necessary articulation between research institutions and the productive sector.

Some of the evidences supporting the argument, present in the interview discourse, were:

[...] When economic policy is good, when the country is going through a favorable economic period, then it is obvious that companies invest. So it is easier for us to receive these partnerships.

Axial Code: Economic influence (positive or negative)

[...] There is a lot of knowledge within organizations, companies, communities and if you do not do these interactions, you do not reach the frontier of knowledge.

Axial Code: Knowledge is distributed in society

Due to the contextual complexity in which the research groups under analysis are involved, specifically dealing with the phenomenon under study, a more in-depth focus is needed specifically on the characteristics and practices of interactions with companies.

\subsection{Practices}

As a first step to initiate U-I interaction, it is necessary to promote the initial contact between these two actors. According to the reports of the researchers and directors of the innovation agencies, it is noticeable that this movement of seeking interaction is mainly coming from networking. These contact networks can start at the undergraduate student, when he/she is working in a certain company and encounters some point of intersection between the company and the university.

Once the communication is initiated, it is necessary to insert a support agent in the U-I interaction, who places itself as intermediary in the relations. From the interviews, the innovation agencies have this role of acting as an interceptor between the U-I, providing managerial and legal support, from the negotiation phase until the conclusion of the U-I collaboration. Regarding this aspect, two practices are highlighted by the managers of agencies that aim to facilitate interaction: (1) The professionalization and training of their employees and also (2) the insertion of market practices as internal dynamics, specifically compliance policies. For an interviewee, both employee training and market practices make the company relate to the innovation agency, facilitating trust between agents.

Finally, management practices are also considered essential for research groups, given the dynamic and extremely competitive environment of innovation. One of the interviewees points out that the research group was structured "like a company" as a condition of success, with well-defined roles, project management and structuring, as shown in the arguments of the interviewees:

[...] The student who goes to work for the company and brings it into the university.

Axial Code 1st. order: Networking as the main interaction channel.

Axial Code 2nd. order: Students as a U-I intermediation channel.

[...] Today the competing groups are very well organized, you see that it is almost a company with well-defined and structured roles, very strong project management. This is increasingly determining the success of the research and the high-level group.

Axial Code: Management practices in research groups

\section{University- industry interaction}


U-I collaboration encourages agents to become more competitive, since only companies focused on innovation and highly organized research groups are able to meet the demands of the market. Economic development is also a consequence of interaction, since research and development generate a product that goes to the market, becoming an innovation. Another consequence mentioned was the training of human resources through knowledge sharing. Inserted as a benefit from these mentioned factors is transfer of technology that, for the interviewees, presents itself as the synthesis of the main consequences of the U-I interaction. Another benefit pointed out was that, when interacting with universities, companies can focus on their main activities, passing on activities that can be analyzed and developed by universities. Cumulative learning was also cited as a benefit of U-I interaction, in the sense that more collaborations are made, greater the learning for future work. The evidences supporting the argument are:

[...] No university reaches the frontier of knowledge by being closed. It needs public-private partnerships to be able to compete on a global scale and reach the frontier of knowledge.

Axial Code 1st. order: Participants become more competitive for the market Axial Code 2nd. order: Technology transfer

[...]For companies, we see that it is a way for them to gain more time, not to use their entire structure to carry out these studies. Instead of working on problems, she can focus on her core activity and not the middle activities.

Axial Code: Companies focus on core activities

\subsection{Challenges/barriers}

Even though they are aware of the consequences and benefits of the U-I interaction, the interviewees reported numerous challenges to be tackled until the "ideal scenario" of collaboration between universities and companies is reached. One of the most present barriers in the speeches was the bureaucracy involved in the U-I interaction. Among the 12 interviewees, all said they were dissatisfied with the excess of bureaucracy involving the U-I interaction process. Respondents attribute the excess of bureaucratic procedures to the lack of legal certainty. It is worth mentioning that this insecurity is placed on all management actors (universities, companies and the State). Another consequence of legal uncertainty is mistrust, a factor considered extremely important in an interaction between universities and companies.

The excessive bureaucracy and normative procedures also result in the difficulty of negotiating patents and Intellectual Property (IP). One interviewee exemplified this situation, reporting that he lost a partnership due to complications in the IP negotiation. Other barriers resulting from legal uncertainty are the researchers' difficulty in allocating resources from interaction with companies.

Another obstacle is the lack of knowledge regarding the benefits of promoting collaboration with external participants (e.g. industries, other universities, institutes). This barrier is directly linked to the ideological differences and personal perspectives of individuals internal to the university. According to the interviewees, individuals opposed to the interaction "(...) think that we are going to sell the public university" (INTERVIEWEE 05). Thus, the benefits of promoting interaction with companies do not seem to be a consensus among university professors, since many condemn those who have projects in partnership with the private sector.

Due to the contextual differences, many researchers and directors of the innovation agencies report that the different expectations between universities and companies are a 
great barrier to interaction. While the researcher aims to develop a thesis or dissertation with a student (which can last from 2 to 4 years), the company wants to have its problem solved as quickly as possible.

Finally, another barrier is the difficulty of company employees in "accepting" knowledge from external entities such as the university. The syndrome not invented here can create obstacles for the team in interacting with the research groups. The evidences supporting the argument are:

[...] from the experience we have, there is a lot of bureaucracy. I think there must be rules, in fact the company itself will not do something without a contract. But there are sometimes a number of rules that are impossible to follow.

Axial Code 1st. order: Legal uncertainty (of universities, companies and the State) Axial Code 2nd. order: Excessive bureaucracy (from universities and companies)

[...] On the company side, there is no trust on the university and so they do not share its data.

Axial Code 1st. order: Legal uncertainty (of universities, companies and the State) Axial Code 2nd. order: Mistrust between actors

[... .] when you propose something new, there is what they call "not invented here", so if you propose something different, sometimes it creates a disturbance for the company, because they have a group there that should have invented. But they are unable to invent, so this group boycotts.

Axial Code: Not invented here syndrome (NIH)

\subsection{Bases for an ideal relationship}

It was possible to perceive that there is a great effort both on the part of the researchers and on the part of the managers of the innovation agencies in developing and leveraging collaboration networks due to the technical application and generalized contribution to the development of innovations. In view of the challenges and barriers to be overcome externally and internally, respondents were asked to identify an ideal scenario that, in their perspective, would leverage U-I interactions.

A preponderant factor for the interviewees was the need to strengthen the ties between the Triple Helix (Industry-Government-University). The joint effort can promote greater trust and flexibility between actors in the interaction. In innovation environments that are inherently unpredictable and where risk is a common variable, trust is a valuable mechanism among agents and, consequently, could promote greater flexibility in the negotiations between universities and companies.

Another necessary factor for the "ideal scenario" is greater legal certainty. This could reduce bureaucratic procedures and also make the process more agile. Finally, the last factor that deserves distinction is the mention of open innovation in response to the promotion of U-I interaction. These factors can be better understood by analyzing the evidences:

[...]I see that the role of federal and state governments, mainly projects that the state does a little, the company a little and the university gives another little would be the projects that go easier in the direction of strengthening the triple helix.

Axial Code 1st. order: Strengthening of the Triple Helix

Axial Code 2nd. order: Trust between all actors

Axil Code 3rd. order: Flexibility between actors

[...] With companies I see, in its own trajectory it is increasingly thirsty for open innovation. Ideal scenario would be to invest in this open perspective.

Axial Code: Stimulating open innovation

\section{University- industry interaction}




\section{Revisiting the literature}

The development of an explanatory conceptual model (based on Grounded Theory) emerges from the access to information collected in the field, combined with the researcher's prior knowledge on the area of the investigated theme (Corbin \& Strauss, 2015). Since the present research sought to understand how U-I interaction process occurs in the southern Brazilian scenario, in this section we discuss some main findings of the research after comparing it with the existing literature. Based on this approximation, it was possible to identify gaps in the literature about U-I interaction, revealing future research paths and opportunities for further study.

\subsection{Opportunities for further study}

The essential role of U-I interaction as a generator of innovation is widely recognized, directly affecting the economic development of a nation (Lehmann \& Menter, 2016; Albats et al., 2018; Lemos \& Cario, 2017). However, there is a lack in the literature on the inverse relationship, that is, the impact of economic reality on U-I collaborations. According to the interviewees, in times of economic crisis, the probability of investments by companies in collaboration with universities is very low. Because of the apparent direct effect that the "health" of the economy has on interactions between the U-I, this point is highlighted for future research.

Little attention was paid to the need for management practices in research groups. This criterion was placed by the interviewees as one of the main success factors for the success of the U-I interaction. Research groups that function as companies, with network structure, well-defined functions, team and time management, are able to compete internationally with other agents for collaboration with companies. The existing literature discusses the importance of project management in managing collaboration (Fernandes, Pinto, Araújo, \& Machado, 2020; Fernandes \& O'Sullivan, 2021). However, the professors responsible for the management of the research group, rarely have management training or knowledge on that area.

Among the benefits cited in the literature (Scandura, 2016; Freitas et al., 2013; Chau, Gilman, \& Serbanica, 2017; Lemos \& Cario, 2017) there is a lack of discussion on the possibility of companies focusing their efforts on core activities. In the interaction with universities, the research and development necessary to improve and open new activity fronts would be carried out on an outsourced basis by the research groups. Understanding the relationship between the cost-benefit of this mechanism is relevant to demystify the U-I interaction, encouraging more and more agents to undertake efforts for joint collaboration.

Although the Not Invented here syndrome is present on open innovation literature (Chesbrough, 2003; Van de Vrande, De Jong, Vanhaverbeke, \& De Rochemont, 2009; Dabrowska \& Savitskaya, 2014), it is only superficially mentioned in U-I interaction scenario. According to Dabrowska and Savitskaya (2014), this syndrome refers to a negative attitude towards knowledge that originates from an external source to the institution itself. The NIH syndrome is partly based on an attitude of xenophobia (Chesbrough, 2006) - fear and rejection of something from outside. This topic deserves scientific deepening since according to the interviewees, this "phobia" and boycott of external ideas arise mostly from employees of companies that collaborate with universities. It is possible to understand this type of behavior between two companies that collaborate through open innovation, both aiming at profit. However, it is not clear why this syndrome can manifest itself in contexts where the actors do not have the same objectives, such as research groups and companies.

Finally, as a last opportunity for further research in the future is the discussion of the legal norms for the U-I interaction process. Expanding the knowledge of the actors involved is one of the ways to promote legal certainty among agents, a fundamental factor in collaborative activities (Xu, Zhou, Xu, \& Li, 2014; Lauritzen \& Karafyllia, 2019). 


\section{Final considerations}

The growing demand for innovation and increasingly complex products and services demands that companies seek new sources of information and knowledge. Interacting with universities is a widespread mechanism and an important means of facing an increasingly competitive market. Even though it's important, the interaction between universities and companies is still a cloudy theme, since it deals with issues such as subjectivity, contextuality and complexity of the elements that interact. An important way to deal with this challenge is to increase knowledge about the characteristics of U-I interactions.

This work aimed to analyze the U-I interaction in innovation ecosystems. The problem under study addresses how agents can operate in U-I interactions to enhance the connections specifically in the aspect of operational mechanisms of an innovation ecosystem.

The results showed that the university-company interaction is influenced by several factors, such as: Networking, legal support, facilitating agents, management practices. Some act as facilitators, others act as inhibitors, preventing the development of interaction between actors or restricting its results.

Despite this, some other factors were identified for the improvement of U-I relationships, such as: strengthening of triple helix, greater legal certainty and encouragement of open innovation.

\subsection{Theoretical contributions}

This is one of the first studies to systematically address the U-I interaction using Grounded Theory as a research strategy. The abductive approach allowed to study the actors inductively, represented as a cognitive map and then ask how the theory could explain this, subsequently putting all these possible theories to test by collecting more data to determine the most plausible explanation, building a circumscribed substantive theory to those actors, given the respective context in which they present themselves. The comparison of the conceptual model explained with the U-I interaction theory allowed the verification of theoretical gaps and the consequent opening of several lines for future inquiry. This research also contributes to the flow of literature that links U-I interaction and R\&D efforts to Open Innovation and Trust.

The external validity of the model goes beyond the limits of southern Brazilian scenario, since the main evidences are supported by the literature. Thus, it could serve as a map of the important factors to be recognized in future research on U-I interaction in other regions and countries. Among the twenty and four main evidences, seven do not have theoretical supportEconomic influence on the U-I interaction, Actors seek to invest in innovation, Management practices in research groups, Companies focus on end activities, Failure in the teacher performance evaluation system certain area of knowledge, NIH Syndrome and Greater legal certainty. From this evidences, it was possible to trace paths for future research.

\subsection{Practical contributions}

From the analysis of the interviews with managers of research groups and directors of the innovation agencies, an explanatory conceptual model was generated, later validated and compared with the literature. This made it possible to derive six strategies aimed at developing U-I interaction. Each of these strategies is explicitly linked to one or more causes of the challenges and barriers pointed out by the interviewees and discussed through excerpts extracted from the interviews.

It was discovered that by strengthening the role of government entities through intermediary agents and also stimulating trust between the actors, it is possible to strengthen the Triple Helix, which Cai and Etzkowitz (2020) put as factor to reinforce the transition from an industrial to a knowledge-based society. Trust between agents is placed as a foundation

\section{University- industry interaction}


element in this context and, according to Bürger and Roijakkers (2021), it can be built through a guide based on social exchange and proximity.

In addition, using open innovation strategies on the part of both universities and companies can be fundamental to speed up processes, which can soften the barriers imposed mainly by the different expectations among the actors. Open Innovation can also be leveraged by sharing equipment between partners, as in the case of facilities, courses and human resources provided by research institutions. Or in the case of horizontal collaborations, which would also benefit companies by mitigating the adverse relationships that many often characterize the U-I interaction. By using and investing in Open Innovation, according to Striukova and Rayna (2015), universities can act as a reliable intermediary to bring together various parties and allow them to collaborate, showing the way for other partners, especially when it comes to controlling and sharing intellectual property. This means that public policies related to universities must be adapted to recognize this new role and further develop the central position of universities in the innovation ecosystem.

Finally, we emphasize the importance of stimulating the legal education of all agents (universities, industries and government), in order to demystify the rules that structure the U-I collaboration process. As education is one of the first missions of universities, it is understood that this movement of legal instruction may come from this agent, disseminating and sharing legal knowledge, consequently reducing insecurities and deadlocks in the construction of contracts that affect productivity in collaborations.

\subsection{Limitations}

We recognized that this study has several limitations. First, the number of interviews conducted for this study is probably not large enough to allow a solid generalization. While the small sample size and the heterogeneity among the universities interviewed did not allow full saturation to occur (especially with regard to the context and interaction practices defined by each university), a significant level of saturation with respect to the challenges and barriers was observed. Thus, although this study cannot confirm that all universities of a certain type apply the same strategies in relation to the U-I interaction, it emphasizes that different universities seem to have a common understanding of the barriers faced and suggestions for overcoming them.

The main objective of this study was to analyze the U-I interaction in innovation ecosystems, since this initial work was fundamental to identify the key elements to be explored in subsequent research. Consequently, the results obtained must be understood as indicative and with the objective of guiding new studies.

A second limitation is that only "one side of the story" (from the universities) was considered. However, the insights provided by this study are particularly significant, as the interviewees were the central agents of interaction with companies at their respective universities. Therefore, the views reported in this study are what "drive" U-I collaborations at universities participating in this study.

\section{References}

ACATE (2020). Tech report. available at: https://www.techreportsc.com/.

Albats, E., Fiegenbaum, I., \& Cunningham, J. A. (2018). A micro level study of university industry collaborative lifecycle key performance indicators. The Journal of Technology Transfer, 43(2), 389-431.

Bardin, L. (2014). Content analysis. São Paulo: Linguística.

Bernardino, C. F., Debortoli, J. V., Veloso, W. G. R., Nunes, A. G., \& de Assis, L. B. (2020). Triple helix analysis from Fapemig data for the last 10 years. Innovation and Management Review, 17(4), $431-446$. 
Bürger, R. E., \& Roijakkers, N. (2021). Developing trust between partners in collaborative R\&D projects. In Managing collaborative R\&D projects. Berlin: Springer-Nature.

Cai, Y., \& Etzkowitz, H. (2020). Theorizing the triple helix model: Past, present, and future. Triple Helix, 7(2-3), 189-226.

Chesbrough, H. W. (2003). Open innovation: The new imperative for creating and profiting from technology. Harvard Business Press.

Chesbrough, H. (2006). Open innovation: A new paradigm for understanding industrial innovation. Open Innovation: Researching a New Paradigm, 400, 0-19.

Chau, V. S., Gilman, M., \& Serbanica, C. (2017). Aligning university-industry interactions: The role of boundary spanning in intellectual capital transfer. Technological Forecasting and Social Change, 123, 199-209.

Corbin, J., \& Strauss, A. (2015). Basics of qualitative research: Techniques and procedures for developing grounded theory. Sage Publications.

Dabrowska, J., \& Savitskaya, I. (2014). When culture matters: Exploring the open innovation paradigm. International Journal of Business Innovation and Research, 8(1), 94-118.

de Souza, T. A., Antunes, L. G. R., da Silva Azevedo, A., Angélico, G. O., \& Zambalde, A. L. (2019). Innovative performance of Brazilian public higher educational institutions: analysis of the remuneration of research groups and companies. Innovation and Management Review.

De Vasconcelos Gomes, L. A., de Faria, A. M., Borini, F. M., Chaparro, X. A. F., Dos Santos, M. G., \& Amaral, G. S. G. (2021). Dispersed knowledge management in ecosystems. Journal of Knowledge Management, 8(1), 94-118.

Edquist, C. (2010). Systems of innovation perspectives and challenges. African Journal of Science, Technology, Innovation and Development, 2(3), 14-45.

Eisenhardt, K. M., \& Graebner, M. E. (2007). Theory building from cases: Opportunities and challenges. Academy of Management Journal, 50(1), 25-32.

Etzkowitz, H., \& Leydesdorff, L. (2000). The dynamics of innovation: From national systems and "mode 2" to a triple helix of university-industry-government relations. Research Policy, 29(2), $109-123$.

Fagerberg, J., Lundvall, B. A., \& Srholec, M. (2018). Global value chains, national innovation systems and economic development. The European Journal of Development Research, 30(3), 533-556.

Fernandes, G., \& O'Sullivan, D. (2021). Benefits management in university-industry collaboration programs. International Journal of Project Management, 39(1), 71-84.

Fernandes, G., Pinto, E. B., Araújo, M., \& Machado, R. J. (2020). The roles of a programme and project management office to support collaborative university-industry R\&D. Total Quality Management and Business Excellence, 31(5-6), 583-608.

FIEC (2020). FIEC Innovation index of the states, available at: https://arquivos.sfiec.org.br/ nucleoeconomia/files/files/Indice\%20fiec\%20de\%20Inovacao/Indice-FIEC-Inovacao_2020_ V10.pdf.

Fioravanti, V. L. S., Stocker, F., \& Macau, F. (2021). Knowledge transfer in technological innovation clusters. Innovation and Management Review, Vol. ahead-of-print No. ahead-of-print. doi:10. 1108/INMR-12-2020-0176.

Fischer, B. B., Schaeffer, P. R., \& Vonortas, N. S. (2019). Evolution of university industry collaboration in Brazil from a technology upgrading perspective. Technological Forecasting and Social Change, 145, 330-340.

Freeman, C. (1995). The "national system of innovation" in historical perspective. Cambridge Journal of Economics, 19(1), 5-24.

Freitas, I. M. B., Marques, R. A., \& e Silva, E. M. D. P. (2013). University-industry collaboration and innovation in emergent and mature industries in new industrialized countries. Research Policy, 42(2), 443-453.

\section{University- industry interaction}



Belo Horizonte: Cedeplar.

Lauritzen, G. D., \& Karafyllia, M. (2019). Perspective: Leveraging open innovation through paradox. Journal of Product Innovation Management, 36(1), 107-121.

Lehmann, E. E., \& Menter, M. (2016). University-industry collaboration and regional wealth. The Journal of Technology Transfer, 41(6), 1284-1307.

Lemos, D., \& Cario, S. A. F. (2017). The national and regional innovation systems and their influence on university-business interaction in Santa Catarina. REGE-Revista de Gestão, 24(1), 45-57.

Lundvall, B. A. (2016). National systems of innovation: Towards a theory of innovation and interactive learning. In The learning economy and the economics of hope (Vol. 85).

Nelson, R. R., \& Rosenberg, N. (1993). Technical innovation and national systems. National Innovation Systems: A Comparative Analysis, 1, 3-21.

Olso Manual - OECD (2018). The measurement of scientific and technological activities. Proposed guidelines for collecting an interpreting technological innovation data (Vol. 30). available at: https://www.oecd-ilibrary.org/docserver/9789264304604-en.pdf?expires $=1628525492 \& i d=i d \&$ accname $=$ guest\&checksum $=$ 0F3F99116D0D439431838932E066C53C.

Paranhos, J., \& Perin, F. S. (2018). Relacionamento universidade-empresa no setor farmacêutico: duas pesquisas comparadas. Experiências de interação universidade-empresa no Brasil. Belo Horizonte: Cedeplar.

Pinho, M. (2018). More than is supposed, less than is needed: Relations between universities and companies in Brazil. In Experiências de interação universidade-empresa no Brasil. Belo Horizonte: Cedeplar.

Puffal, D. P., Ruffoni, J., \& Spricigo, G. (2021). Empirical evidence for Brazilian firms in terms of university-industry interaction, public funding and innovation outcome. International Journal of Innovation Management, 25(4), 2150040.

Rajalo, S., \& Vadi, M. (2017). University-industry innovation collaboration: Reconceptualization. Technovation, 62, 42-54.

Scandura, A. (2016). University-industry collaboration and firms' R\&D effort. Research Policy, 45(9), $1907-1922$.

Striukova, L., \& Rayna, T. (2015). University-industry knowledge exchange: An exploratory study of open innovation in UK universities. European Journal of Innovation Management, 18(4), 471492. doi:10.1108/EJIM-10-2013-0098.

Suzigan, W., \& Albuquerque, E. D. M. (2011). The underestimated role of universities for the Brazilian system of innovation. Brazilian Journal of Political Economy, 31, 3-30.

Van de Vrande, V., De Jong, J. P., Vanhaverbeke, W., \& De Rochemont, M. (2009). Open innovation in SMEs: Trends, motives and management challenges. Technovation, 29(6-7), 423-437.

Xu, G., Zhou, Y., Xu, L., \& Li, S. (2014). Effects of control in open innovation: An empirical study of university-industry cooperation in China. International Journal of Technology, Policy and Management, 314(4), 346-363.

\section{Corresponding author}

Rafaela Bürger can be contacted at: rafaelaescobarburger@gmail.com

For instructions on how to order reprints of this article, please visit our website:

www.emeraldgrouppublishing.com/licensing/reprints.htm

Or contact us for further details: permissions@emeraldinsight.com 